\title{
Disodium cromoglycate in the treatment of chronic proctitis
}

\author{
R. V. HEATley, B. J. CAlCRAfT, J. RHODES, E. OWEN, AND B. K. EVANS \\ From the Departments of Gastroenterology, Pathology, and Pharmacy, University Hospital of Wales, \\ Cardiff
}

SUMMARY The effect of topical disodium cromoglycate (DSCG) has been examined in 30 patients with chronic active proctitis using a double-blind crossover trial. Each treatment period was four weeks and patients were given DSCG $200 \mathrm{mg}$ by enema twice daily and $100 \mathrm{mg}$ orally three times each day. Twenty-six patients completed the trial successfully, 14 responded to DSCG treatment, two improved with placebo, and 10 responded to neither.

Patients who responded to DSCG had significantly more eosinophils in their rectal biopsies than those who failed to respond and in some instances the counts were very high. The findings support the hypothesis that an allergic reaction is important in the pathogenesis of proctitis.

Disodium cromoglycate (DSCG) is of proven clinical value in allergic bronchial asthma where it is thought to reduce the degranulation of mast cells in bronchial mucosa (Pepys, Hargreave, Chan, and McCarthy, 1968). Chronic proctitis is an inflammatory condition of unknown aetiology affecting the rectal mucosa. In a related condition, ulcerative proctocolitis, mast cell degranulation is a common feature in rectal biopsies (Bercovitz and Sommers, 1966). It is therefore pertinent to examine whether DSCG, if given topically, would have a beneficial effect in patients with proctitis. Proctitis is a particularly suitable condition to examine because in addition to recording any symptomatic response, the rectal mucosa can be both inspected and biopsied directly. A randomized, double-blind crossover trial was designed to examine the effect of this compound in a group of patients with chronic proctitis.

\section{Methods}

\section{PATIENTS}

Thirty patients with chronic proctitis were included in the trial but four were subsequently withdrawn. All had active symptoms which included rectal bleeding, the passage of mucus, and a change in bowel habit, usually with increased frequency. In all the rectal mucosa was abnormal on sigmoidoscopy. The subsequent details refer to the 26 patients

Received for publication 21 April 1975. who completed the trial, nine of whom were male and 17 female patients. The mean age was 39 years (range 18 to 74 years). The duration of previous symptoms was between three and 120 months (mean 33 months); 20 of the patients had had symptoms for more than one year. The severity of symptoms during the first five days of the trial is given in fig 1; half of the patients had blood loss on most days with between two and four stools daily. Four patients continued with additional therapy, taking between 0.5 to $2 \mathrm{~g}$ of sulphasalazine throughout the trial. One of these patients also had a predsol enema each day and a further two patients received predsol enemas without sulphasalazine throughout the trial. All had a normal barium enema examination during the previous six months.

DESIGN OF TRIAL

Patients entered the trial in a randomized way and received treatment with DSCG and a placebo, each for a period of four weeks. Neither the clinician nor the patient was aware of which treatment was being given. In the first period, they received either DSCG or placebo and in the second period the alternative treatment. One hundred mg of DSCG was given in gelatine capsules three times daily by mouth and $200 \mathrm{mg}$ was self administered as an enema, after first dissolving the DSCG in $40 \mathrm{ml}$ of warm tap water. The placebo was glucose in identical capsules.

Patients were assessed at the commencement of the trial and then after four and eight weeks. On each 

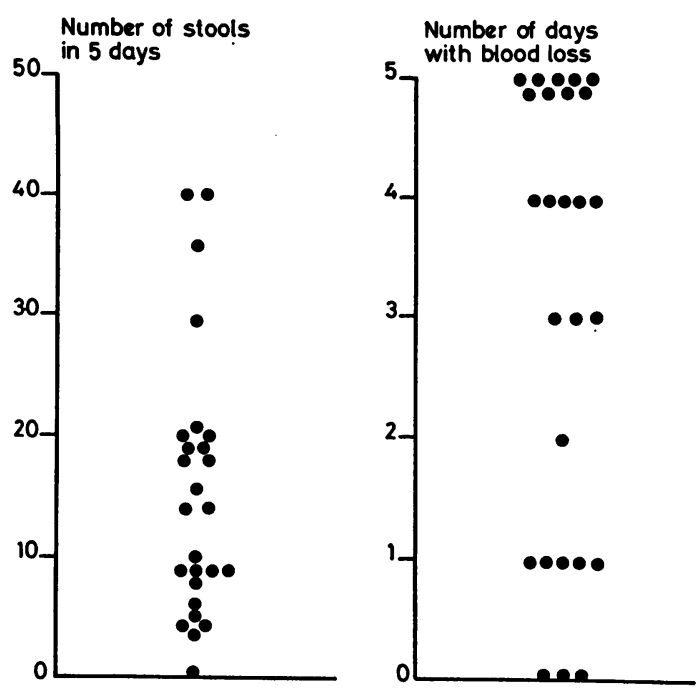

Fig 1 The severity of symptoms for each patient during the first five days is shown in the number of stools and the number of days on which blood loss occurred.

occasion sigmoidoscopic examination was carried out using a standard Lloyd-Davies instrument. A system of grades was used similar to that described by Baron, Connell, and Lennard-Jones (1964), for this has been shown to give little observer variation; grade I was normal mucosa, grade II hyperaemic mucosa with loss of the normal vascular pattern, in grade III there was bleeding on light contact or spontaneously, and in grade IV there were severe changes with an excess of mucus, pus, mucosal haemorrhages, and occasional ulceration. The severity was noted at varying distances from the anal margin, for the most severe change was commonly limited to the lower rectum. Each patient was followed by the same clinical observer during the trial. A rectal biopsy was taken at each sigmoidoscopic examination from a point on the anterior rectal wall about $8 \mathrm{~cm}$ from the anal margin.

During each four-week period patients recorded on a diary card the frequency of bowel motions each day and the occurrence of rectal bleeding. The records from the last 14 days of this four-week period were subsequently used for analysis; this effectively interposed two weeks between the assessment periods. In addition, at the end of each four-week period patients indicated their clinical progress by choosing one of the following words: excellent, good, fair, bad, or terrible; these were taken as an overall assessment by the patient and were used in subsequent analyses.

\section{HISTOLOGY}

Rectal biopsies were examined without knowledge of the patient or treatments given. The acute inflammatory reaction was graded as normal, moderate, or severe, using paraffin sections stained with haematoxylin and eosin. This was based on the degree of acute inflammatory infiltrate of the lamina propria, crypt abscesses if these were present, and early migration of polymorphs across the basement membrane of epithelial tubules. In addition, sections were stained with carbol chromatrobe which specifically stains eosinophil cells. Eosinophil counts were made over five high-power fields. A further section was stained with toluidine blue to stain mast cells. Twelve biopsies were taken from control patients who did not have inflammatory bowel disease; most of them had had a recent change in bowel habit. These biopsies were used for comparison and in none did the eosinophil count exceed 10 cells per five high-power fields.

Blood was taken to measure the erythrocyte sedimentation rate (Westergren), haemoglobin, total white cell count, absolute eosinophil count, and serum IgE (Johansson, Bennich, and Wide, 1968).

\section{Results}

The three measurements of clinical response were a change on sigmoidoscopic examination, details from the diary card of bowel frequency and blood

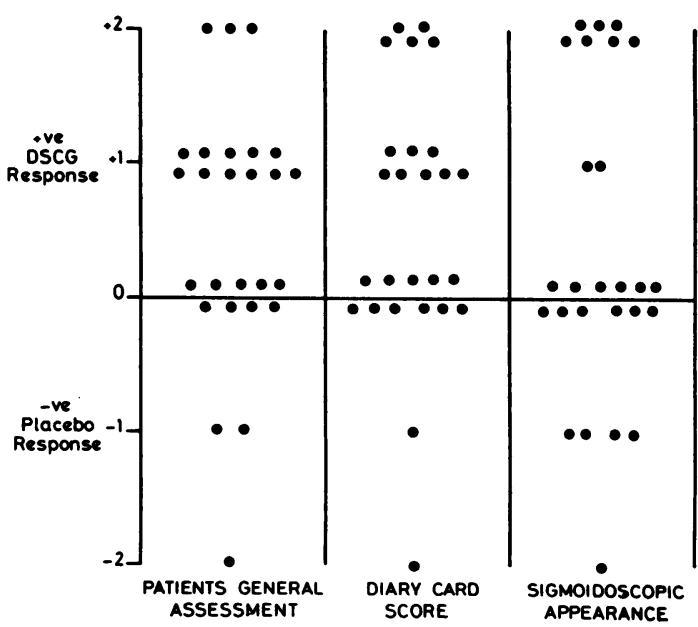

Fig 2 Change in the clinical severity of proctitis for each patient was based on the patient's assessment, the diary card record of stool frequency and blood loss, and the sigmoidoscopic appearance. The two treatment periods were compared and scored +1 or +2 for a favourable response to $D S C G$, and -1 or -2 for a placebo response. 
loss, and the patient's general assessment of each period. Each patient was assessed without knowledge of the order in which each treatment was given. For each of these assessments, if patients were clearly better during one period compared with the other this was given a score of 2 ; where DSCG was given in that period the score was +2 and where the placebo was given, -2 . Clinical benefit during one period which was less striking was given a score of $1 ;+1$ if this occurred with DSCG, and -1 with placebo. If there was no difference between the two periods the score was 0 . A summary of these assessments is given in fig 2 and the total for each patient is also shown in figure 3. If one accepts that total scores between -1 and +1 represent no significant clinical response and that patients with a score of +2 or more show response to DSCG, then 14 responded to DSCG, 10 showed no change, and two responded to the placebo. In view of these clinical findings, we have divided the patients into two groups, 14 of whom responded to DSCG and 12 who did not show a beneficial clinical response.

There was no significant change in the haemoglobin, white cell count, or the ESR during the trial nor any association with treatment. The total eosinophil count in blood was initially less than $400 / \mathrm{cmm}$ in all except one patient with a median of $187 / \mathrm{cmm}$ (range 61 to 415). There was no consistent change in the eosinophil count associated with the patients' clinical progress.

Values for the initial serum IgE varied between 29 and 594 IU per litre (geometric mean 145); there was no significant difference between the 'responders'

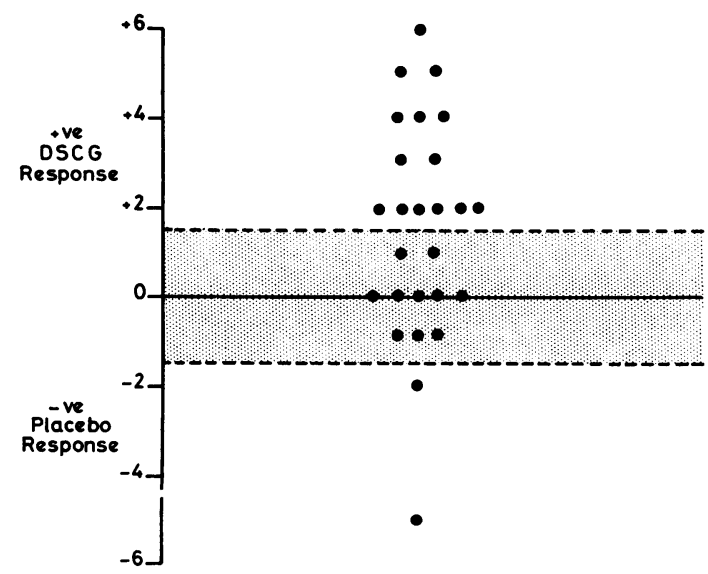

Fig 3 Total score for the change in severity of proctitis based on the patient's general assessment, the diary card, and sigmoidoscopic appearances. The shaded zone includes those patients who showed little response to either DSCG or placebo during the trial. (geometric mean 162) and the 'non-responders' (geometric mean 123). The serum values did not change significantly in either group of patients throughout the trial period.

\section{HISTOLOGY OF RECTAL BIOPSIES}

The eosinophil count per five high-power fields (hpf) varied between 0 and 110 (fig 4). The mean value for the first biopsies was 49 (range 11 to 100) in 'responders' and 16 (range 0 to 45) in 'non-responders'; the difference between these figures is significant ( $<<0.006$ ) (fig 4). Changes in the tissue eosinophil count which occurred in those changes which occurred in those who responded to DSCG were marked. During each treatment period there was either an increase or a decrease in the count. There was a relative increase during the placebo compared

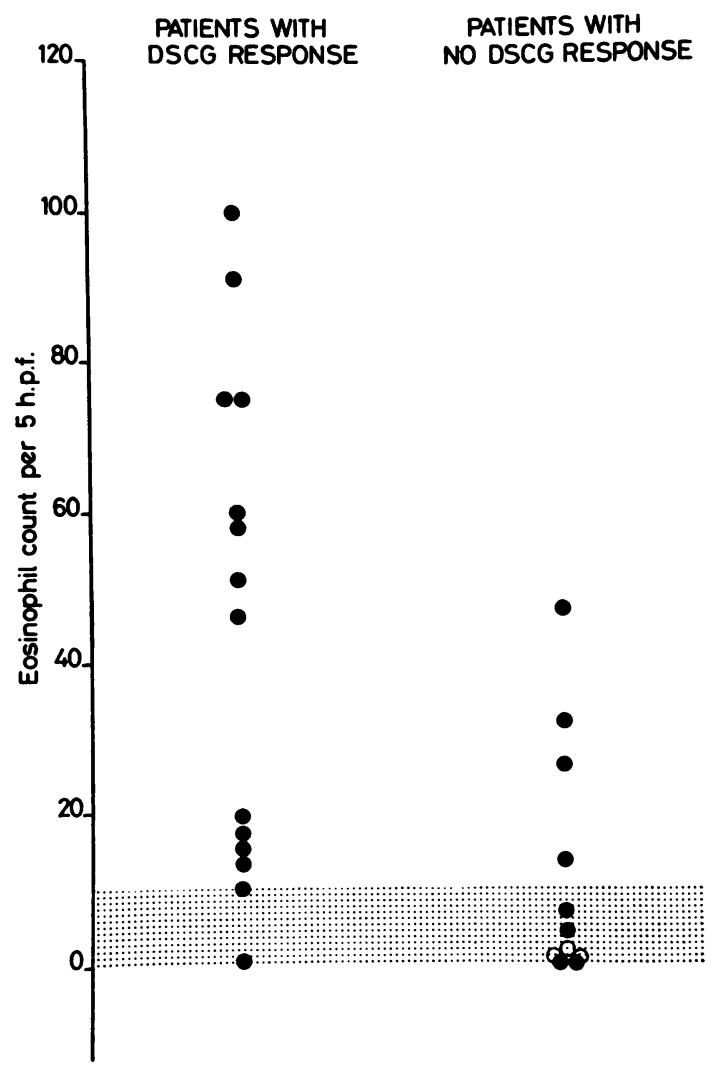

Fig 4 Each point represents the eosinophil count from five high-power fields in rectal biopsies taken at the commencement of the trial $\bigcirc$; three initial biopsies were unsatisfactory and the second biopsy result is given $\bigcirc$. The counts are given for patients who responded to DSCG and those who did not respond. The shaded zone is the normal range. 
with the DSCG period in nine and a relative decrease in four. The changes which occurred in 'nonresponders' were variable; in three there was little change, in three there was a relative increase, and in two a relative decrease in the placebo period.

Nine of the 14 patients who responded to DSCG had either moderate or severe inflammatory changes in the rectal biopsies. Four of the 12 who did not respond also showed acute inflammatory changes, and, in a further patient who had severe proctitis, repeated attempts to obtain satisfactory biopsies were unsuccessful. There was a poor correlation between the mucosal inflammatory reaction and changes in the clinical response and sigmoidoscopic appearance.

The number of mast cells counted per five highpower fields ranged between 0 and 39; in 43 of 63 biopsies the count was less than three per five highpower field and showed no consistent change with clinical response.

Four patients were withdrawn from the trial because they either failed to cooperate or developed an unrelated illness; no side effects from DSCG were encountered.

\section{Discussion}

Disodium cromoglycate has a topical action on the bronchial mucosa and reduces the effect of inspired antigens in some patients with extrinsic asthma (Pepys, Hargreave, Chan, and McCarthy, 1968). The normal sequence of events is that the interaction of antigen and antibody causes mast cell damage (Orr, Pollard, Gwilliam, Jessie, and Cox, 1970). These cells then break down, releasing histamine, serotonin, and 5-hydroxytryptamine, which cause tissue damage. Disodium cromoglycate stabilizes the mast cells in bronchial mucosa and blocks these events. The only report of a related effect in the gastrointestinal tract is a beneficial response to DSCG in four infants with gastrointestinal protein intolerance (Freier and Berger, 1970). The pathogenesis of both proctitis and ulcerative colitis remains unknown and the possibility that an allergic component may play a significant role has frequently been suggested (Rider, Moeller, Devereaux, and Wright, 1960; Wright and Truelove, 1965). If there is such a component, then DSCG may be of value. Since the compound remains unchanged during its transit through the gastrointestinal tract and less than $2 \%$ is absorbed, oral administration may be effective in lesions of the lower gastrointestinal tract.

Before commencing the trial 14 patients with proctitis were treated for between two to eight weeks with $200 \mathrm{mg}$ three times each day given orally, or
$200 \mathrm{mg}$ twice daily by enema, or a combination of the drug given orally and by enema. Ten patients appeared to show a beneficial response so that we were encouraged to proceed with a controlled trial.

The trial was double-blind and of crossover design which made it a sensitive indicator of any response. The patients showed a positive response to either DSCG, the placebo, or failed to respond to either treatment. Fourteen showed some response to DSCG, two to placebo, and 10 to neither of these. We are particularly concerned with the comparison between those patients who responded to, and those who failed to respond to disodium cromoglycate.

Although patients with ulcerative colitis respond to treatment with corticosteroids, only about $25 \%$ of patients with proctitis can be expected to go into full remission with topical treatment (Lennard-Jones, Baron, Connell, and Jones, 1962). Those with a long history of symptoms appear less likely to respond to this form of treatment (Truelove, 1959). Sulphasalazine may be of additional value in some patients, either by inducing or maintaining a clinical remission. However, because of a failure to respond to conventional treatment, or undesirable side effects in some patients, there is good reason to look for alternative forms of therapy. Compounds like DSCG may have a place in the future management of patients with proctitis.

Disodium cromoglycate acts at a particular point in the inflammatory reaction, and as half of our patients responded to this treatment, we may have identified a part of the inflammatory mechanism in patients with proctitis. In considering other related evidence which supports an allergic component in proctitis, one must consider the data collected from patients with ulcerative colitis. It would seem reasonable to do this because some cases of proctitis later spread to involve the proximal bowel and the condition is then indistinguishable from ulcerative colitis. Both the sigmoidoscopic appearances and the pathology of the two conditions are similar and many authors regard them as the same disease process (Goligher, 1953; Naish, 1953; Hill, 1957; Truelove, 1959; Lennard-Jones, Cooper, Newell, Wilson, and Jones, 1962). Histological changes in proctocolitis include an increase in the number of both chronic and acute inflammatory cells, with a marked increase in eosinophils in some patients; mast cells may also be present in excess and are frequently degranulated. This cellular increase is likely to be important in the pathogenesis of the disease, since during activity, both mast cells and eosinophils are greatly increased but fall to normal with remission (McAuley and Sommers, 1961; Hiatt and Katz, 1962; Bercovitz and Sommers, 1966, Wright and Truelove, 1966). 
Allergic tissue reactions are frequently associated with an increased number of eosinophils (Litt, 1964). These are found in the bronchial mucosa associated with extrinsic asthma and the nasal mucosa in hay fever. Large numbers of eosinophils can sometimes be identified in the stools of infants with milk allergy (Rosenblum and Rosenblum, 1952). The rectal biopsies from our patients with proctitis showed a wide range in their eosinophil content; in only four of 21 patients, all of whom failed to respond to DSCG, were the counts in the normal range; in some instances the counts were very high (fig 4).

The association of proctocolitis with a peripheral blood eosinophilia has also been noted in some patients and this eosinophilia frequently disappears when the inflammatory disease goes into remission (Riisager, 1959; Riis and Anthonisen, 1963; Wright and Truelove, 1966). Thirteen of our patients had a peripheral eosinophil count greater than 200 per $\mathrm{cmm}$ and two greater than 400 per $\mathrm{cmm}$; these are values which would be considered by some to be greater than normal.

The histamine content of tissue involved in an allergic reaction is sometimes considerably increased. The histamine content of rectal mucosa in patients with ulcerative colitis has been examined and is high during a clinical relapse, but falls to normal with clinical remission (Binder and Hvidberg, 1967). The concentration of histamine is proportional to the number of eosinophils present in the surface mucosal exudate. It is quite probable that the high histamine content and eosinophilia in rectal exudates reflect an allergic reaction in the mucosa. The allergic release of histamine from sensitized mast cells may follow an antigen-antibody reaction, and this in turn would be inhibited by disodium cromoglycate. It has even been suggested that the pathology of ulcerative colitis is due to release of histamine into the tissues (McGovern and Archer, 1957). This study provides evidence to suggest that immune mechanisms are important in the pathogenesis of some cases of proctitis and in addition DSCG or similar agents may have some part to play in the routine management of these patients.

We gratefully acknowledge help from many people who made it possible to conduct the study; Mrs V. Jenkins, Mrs B. Pelling and Miss J. Hopson for administrative help, Dr J. W. Keyser in the Depart- ment of Biochemistry, Mr R. G. Newcombe in the Department of Medical Statistics, members of the Department of Medical Illustration, Fisons Limited who supplied the DSCG, and Hoechst Pharmaceuticals Limited for assistance with immunoglobulin estimations.

References

Baron, J. H., Connell, A. M., and Lennard-Jones, J. E. (1964). Variation between observers in describing mucosal appearances in proctocolitis. Brit. med. J., 1, 89-92.

Bercovitz, Z. T., and Sommers, S. C. (1966). Altered inflammatory reaction in nonspecific ulcerative colitis. Arch. intern. Med., 117, 504-510.

Binder, V., and Hvidberg, E. (1967). Histamine content of rectal mucosa in ulcerative colitis. Gut, 8, 24-28.

Freier, S., and Berger, H. (1973). Disodium cromoglycate in gastrointestinal protein intolerance. Lancet, 1, 913-915.

Goligher, J. C. (1953). What is ulcerative colitis? (Letter)Lancet, 2,38.

Hill, J. R. (1957). Ulceration of the rectum and terminal portion of the colon: significance in absence of malignant disease and chronic ulcerative colitis. Arch. Surg., 75, 1029-1035.

Hiatt, R. B., and Katz, L. (1962). Mast cells in inflammatory condition of the gastrointestinal tract. Amer. J. Gastroent., 37, 541 545.

Johansson, S. G. O., Bennich, H., and Wide, L. (1968). A new class of immunoglobulin in human serum. Immunology, 14, 265-272.

Lennard-Jones, J. E., Baron, J. H., Connell, A. M., and Jones, F. A. (1962). A double blind controlled trial of prednisolone-21. phosphate suppositories in the treatment of idiopathic proctitis. Gut, 3, 207-210.

Lennard-Jones, J. E., Cooper, G. W., Newell, A. C., Wilson, C. W. E. and Jones, F. A. (1962). Observations on idiopathic proctitis. Gut, 3, 201-206.

Litt, M. (1964). Eosinophils and antigen-antibody reactions. Ann. N.Y. Acad. Sci., 116, 964-985.

McAuley, R. L., and Sommers, S. C. (1961). Mast cells in nonspecific ulcerative colitis. Amer. J. dig. Dis., 6, 233-236.

McGovern, V. J., and Archer, G. T. (1957). The pathogenesis of ulcerative colitis. Aust. Ann. Med., 6, 68-74.

Naish, J. (1953). What is ulcerative colitis? (Letter) Lancet, 2, 254

Orr, T. S. C., Pollard, M. C., Gwilliam, J., and Cox, J. S. G. (1970). Mode of action of disodium cromoglycate, studies on immediate type hypersensitivity reactions using double sensitization with two antigenically distinct rat reagins. Clin. exp. Immunol., 7, 745-757.

Pepys, J., Hargreave, F. E., Chan, M., and McCarthy, D. S. (1968) Inhibitory effects of disodium cromoglycate on allergen inhalation tests. Lancet, 2, 134-137.

Rider, J. A., Moeller, H. C., Devereaux, R. G., and Wright, R. R (1960). The use of an intramucosal test to demonstrate food hypersensitivity in ulcerative colitis. Acta allerg. (Kbh.), 15, suppl. 7, 486-494.

Riis, P., and Anthonisen, P. (1964). Eosinophilia in peripheral blood and inflammatory exudate in non-specific proctocolitis. Acta med. scand., 175, 85-89.

Riisager, P. M. (1959). Eosinophil leucocytes in ulcerative colitis Lancet, 2, 1008-1009.

Rosenblum, A. H., and Rosenblum, P. (1952). Gastrointestinal allergy in infancy: significance of eosinophils in the stools. Pediatrics, 9. 311-319.

Truelove, S. C. (1959). Suppository treatment of haemorrhagic proctitis. Brit. med. J., 1, 955-958.

Wright, R., and Truelove, S. C. (1966). Circulating and tissue eosinophils in ulcerative colitis. Amer. J. dig. Dis., 11, 831-846.

Wright, R., and Truelove, S. C. (1965). Circulating antibodies to dietary proteins in ulcerative colitis. Brit. med.J., 2, 142-144. 